\title{
Obituary for Prof. Dr. Friedrich Zywietz
}

\section{Research results and accomplishments of the biophysicist Prof. Dr. Friedrich Zywietz (1936-2019)}

\section{Böhm ${ }^{1}$}

Published online: 30 April 2020

(c) Springer-Verlag GmbH Germany, part of Springer Nature 2020

Friedrich Zywietz (Fig. 1) was a deeply committed researcher with a strong orientation towards the clinical application of radiation biology.

Zywietz was born on the 11th of October 1936 in Neidenburg, Masuren, where his father was a farmer. With the territorial changes after the war, the family left Neidenburg in 1945 and settled in Agathenburg/Stade, where Friedrich attended high school and studied physics in Hamburg. In 1966 he was appointed to the research staff of the Department of Biophysics and Radiation Biology at the University Klinikum Eppendorf (UKE) under Professor HA Kunkel. Zywietz later qualified as Dr. rer nat and Dr rer nat habil, and was appointed Professor of Biophysics and Radiation Biology in 1997. He died in October 2019 after a short illness in Stade. His widow, Dr. Sigrid Meinig, has our thoughts and condolences.

In his research, Zywietz dealt with a wide range of fundamental and applied questions. To overcome the problem of reaching deep-seated tumours, he showed that $6 \mathrm{GeV}$ Bremsstrahlung is very promising both in terms of tissue penetration and radiobiological effectiveness [1]. However, introduction of fast neutrons quickly changed these prospects when it became known that the depth dose of high-energy neutrons is very similar to megavoltage X-rays. In the ensuing international excitement about the therapeutic promises of high relative biologic effectiveness (RBE) and low oxygen enhancement ratio (OER) irradiation, many types of neutron sources were explored. By comparing the broad-spectrum $6 \mathrm{MeV}$ d-Be neutron beam in Essen with the monoenergetic $14 \mathrm{MeV}$ d-T beam at Hamburg, Zywietz et al. [2] demonstrated that the RBE of the weaker Essen beam was in fact higher than that of the Hamburg beam

Prof. L. Böhm

lbohm@telkomsa.net

14 Alice's Ride, Pinelands, 7405 Cape Town, South Africa by factors of 1.24 (crypt cell survival) and 1.19 (microdosimetry). The close agreement and consistency of data confirmed the merits of direct intercomparisons for assessing RBE differences between particle radiations of different energy [3].

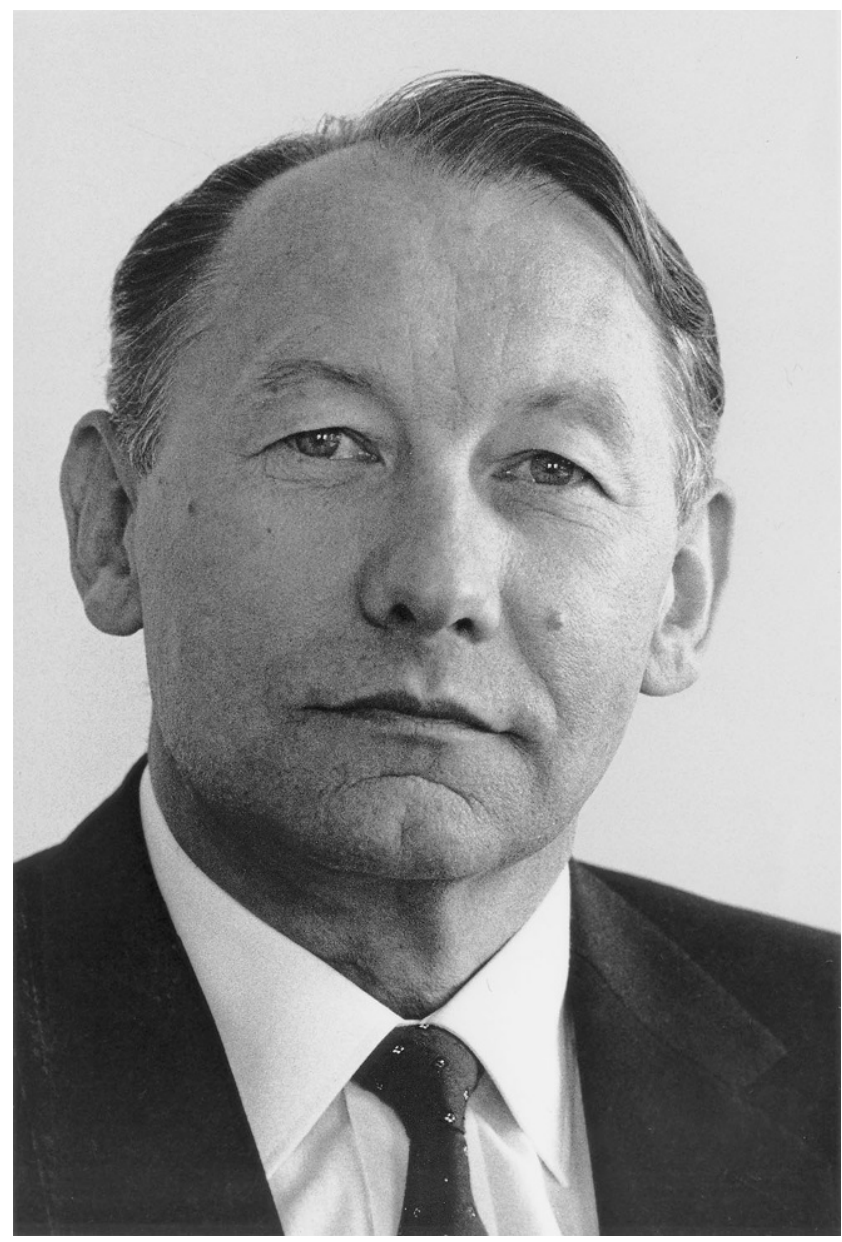

Fig. 1 Prof. Dr. Friedrich Zywietz, Biophysicist (1936-2019) (ㅇ Prof. Dr. Friedrich Zywietz) 
Other clinically relevant topics in Hamburg were the search for irradiation conditions which would generate G2M cells by cell synchronization. However, a lack of cell kinetic data for human tumours made it difficult to attribute this effect to the accumulation of tumour cells in G2M phase [4]. When hyperthermia emerged as a potent adjuvant to irradiation soon thereafter [5], Zywietz used his $\mathrm{R} 1 \mathrm{H}$ tumour model to achieve close coupling of heat and irradiation and thermal enhancements in the region of 1.4 for IR-A irradiation as the heat source [6]. Using the same model, we showed that the vasoactive drug pentoxifylline enhances tumour oxygenation and tumour control [7], while in vitro irradiation of $\mathrm{R} 1 \mathrm{H}$ cells exposes a whole range of other cellular responses largely dependent on p53 status [8].

In the last years of his experimental work, Zywietz studied the influence of irradiation on the vasculature, showing profound deterioration of the epithelium (blebbing) and dependence of tumour hypoxia upon irradiation dose and time [9]. This work attracted much attention in the group of Peter Vaupel, as the 45-Gy threshold identified by Zywietz on the basis of epithelial demise was also seen by Vaupel [10] as the onset of metabolic deterioration indicated by the decline of ATP and increase of glucose in the irradiated tissue. Understanding of the micromilieu is now at the centre of ultra-high-dose rate (FLASH) radiotherapy [11, 12]. Zywietz was supported by the Erwin Braun Foundation and together with Böhm by the Volkswagenstiftung.

To encourage the translation of new mechanistic understanding into the clinic, Zywietz donated a Dissertation Prize for Radiation Biology and Experimental Radiation Oncology (to the Freundes- und Förderkreis at UKE). The first recipient was a student from the group of Professor Kersten Borgmann for a thesis identifying the EGFR mutant vIII as a marker for the sensitivity of glioblastomas to temozolomide. I distinctly remember Friedrich Zywietz being absolutely delighted that his stipulations had been met with such interesting results.

\section{References}

1. Stähler F et al (1969) Dependence of the relative biological efficiency of high energy deceleration radiation upon the layer of matter irradiated. Z Naturforsch B 24(b):1633-1640

2. Zywietz F, Menzel HG et al (1982) A Biological and Microdosimetric Intercomparison of $14 \mathrm{MeV}$ d-T Neutrons and $6 \mathrm{MeV}$ Cyclotron Neutrons. Int J Radiat Biol 42:223-228

3. Gueulette J et al (1996) RBE variation between fast neutron beams as a function of energy. Intercomparison involving 7 neutrontherapy facilities. Bull Cancer Radiother 83:55-63

4. Zywietz F, Jung H (1980) Partial synchronization of three solid animal tumours by X-rays. Eur J Cancer 16:1381-1388

5. Overgaard J (1982) Influence of sequence and interval on the biological response to combined hyperthermia and radiation. Natl Cancer Inst Monogr 61:325-332

6. Zywietz F (1995) Infrarot-A-Hyperthermie als strahlensensibilisierendes Agens bei Bestrahlung oberflächennah liegender Tumoren: Tierexperimentelle Untersuchungen. In: Wärmetherapie mit wassergefilterter Infrarot-A-Strahlung, Grundlagen und Anwendungsmöglichkeiten, 2. Aufl. Hippocrates, Stuttgart

7. Zywietz F et al (2004) Pentoxifylline Enhances Tumor Oxygenation and Radiosensitivity in Rat Rhabdomyosarcomas during Continuous Hyperfractionated Irradiation. Strahlenther Onkol 180:306-314

8. Bohm L (2006) Inhibition of homologous recombination repair with Pentoxifylline targets G2 cells generated by radiotherapy and induces major enhancements of the toxicity of cisplatin and melphalan given after irradiation. Radiat Oncol 2006(1):12

9. Zywietz F et al (1994) Ultrastructural Studies on Tumor Capillaries of a Rat Rhabdomyosarcoma during Fractionated Radiotherapy. Acta Anat 150:80-85

10. Thews $O$ et al (1999) Quantitative changes of metabolic and bioenergetic parameters in experimental tumors during fractionated irradiation. Int J Radiat Oncol Biol Phys 45:1281-1288

11. Levy K et al (2019) Preclinical testing of ultra-rapid FLASH total abdominal irradiation demonstrates survival benefit and decreased gastrointestinal toxicity compared to conventional external beam radiation. J Clinical Oncol 37(15_suppl):3092

12. Hill RP (2017) The changing paradigm of tumour response to irradiation. Br J Radiol 90(1069):200160474 
Hier steht eine Anzeige.

Springer 